\title{
Heterogeneous catalysts for carbene insertion reactions
}

José M. Fraile, ${ }^{* a}$ José A. Mayoral, ${ }^{a}$ Nicoletta Ravasio, ${ }^{b}$ Marta Roldán, ${ }^{a}$ Laura Sordelli, ${ }^{b}$ and Federica Zaccheria ${ }^{\mathrm{b}}$

a Departamento de Química Orgánica, Instituto de Síntesis Química y Catálisis Homogénea (ISQCH), Universidad de Zaragoza - C.S.I.C., E-50009 Zaragoza (Spain)

${ }^{\mathrm{b}}$ Istituto di Scienze e Tecnologie Molecolari, Consiglio Nazionale delle Ricerche, via Golgi 19, I-20133 Milano (Italy)

\footnotetext{
${ }^{*}$ Corresponding author:

José M. Fraile

Departamento de Química Orgánica

Instituto de Síntesis Química y Catálisis Homogénea (ISQCH)

Facultad de Ciencias, Universidad de Zaragoza - C.S.I.C.

C/ Pedro Cerbuna s/n

E-50009 Zaragoza (Spain)

E-mail: jmfraile@unizar.es

Fax: +34 976762077
} 


\begin{abstract}
Copper catalysts supported on silica or silica-alumina are used to promote the insertion of carbenes, coming from methyl phenyldiazoacetate and ethyl diazoacetate, into one C-H bond of THF, constituting the first example of this reaction promoted by a purely inorganic catalyst. $\mathrm{Cu} / \mathrm{SiO}_{2}-\mathrm{Al}_{2} \mathrm{O}_{3}$ leads to better results, regarding yield and catalyst recovery, than with $\mathrm{Cu} / \mathrm{SiO}_{2}$. With the former catalysts yields are similar or even slightly better than those reached in solution using $\mathrm{Cu}(\mathrm{OTf})_{2}$ as the catalyst. These yields are further improved by the addition of an external bis(oxazoline) ligand. The reaction is promoted by $\mathrm{Cu}(\mathrm{I})$, obtained by in situ reduction of $\mathrm{Cu}$ (II) with the diazocompound, therefore different behavior of the catalysts, depending on the support, is related to the different redox properties of the supported $\mathrm{Cu}$ phase. Isolated $\mathrm{Cu}$ (II) species on the surface of $\mathrm{Cu} / \mathrm{SiO}_{2}$ $\mathrm{Al}_{2} \mathrm{O}_{3}$ are easily reduced to $\mathrm{Cu}(\mathrm{I})$, whereas supported $\mathrm{CuO}$ is much more easily reduced to $\mathrm{Cu}(0)$ as shown by EXAFS analysis.
\end{abstract}

Keywords: Carbene insertion; Heterogeneous copper catalysts 


\section{Introduction}

In the last 10 years due to the discovery of versatile and very efficient new copper/ligand systems for the formation of $\mathrm{C}-\mathrm{C}, \mathrm{C}-\mathrm{N}$, and $\mathrm{C}-\mathrm{O}$ bonds that enabled the use of only catalytic amounts of metal under mild conditions $\left(90-110^{\circ} \mathrm{C}\right)$ there has been a spectacular resurgence of interest in Ullmann and Goldberg type, copper catalyzed, coupling reactions [1-3]. Besides an enormous number of homogeneous systems also a few heterogeneous based ones have been set up. As an example, some of us reported the interesting activity of a heterogeneous $\mathrm{CuO} / \mathrm{Al}_{2} \mathrm{O}_{3}$ system for the Sonogashira coupling of aryl iodides with phenylacetylene [4], although extensive copper leaching (around 60\%) did not allow catalyst reuse.

On the contrary, functionalization of $\mathrm{C}-\mathrm{H}$ bonds, and especially with formation of $\mathrm{C}-\mathrm{C}$ bonds, is still a challenge in current chemical research. The metal-catalyzed insertion of carbenes, generated from diazocompounds, is a well established alternative method to functionalize $\mathrm{C}-\mathrm{H}$ bonds [5]. Rhodium homogeneous complexes have been widely used for this kind of reaction, with particular focus on the asymmetric version [6, 7], whereas copper complexes have been more scarcely used [8-15]. Regarding recyclable catalysts, only supported versions of homogeneous catalysts have been described, including Rhcarboxylate [16-18] and bis(oxazoline)-copper [13] complexes. However, to the best of our knowledge, purely inorganic materials have not been used as heterogeneous catalysts for C$\mathrm{H}$ carbene insertion reactions.

Purely inorganic materials have been used as catalysts in the mechanistic related cyclopropanation reaction, for example $\mathrm{Cu}$-exchanged zeolites and clays $[19,20]$ or heteropolyacids [21]. Liu et al. reported excellent yields, up to $94 \%$, in the same reaction by using a $\mathrm{CuO} / \mathrm{TiO}_{2}-\mathrm{Al}_{2} \mathrm{O}_{3}$ catalyst. However, neither detailed characterization of the copper 
phase present at the surface was given nor tests on catalyst stability were reported [22]. Although both cyclopropanation and $\mathrm{C}-\mathrm{H}$ insertion reactions take place through a common copper-carbene intermediate, the mechanism is indeed very different. In the case of cyclopropanation the rate limiting step is the formation of the copper-carbene intermediate [23], whereas in the insertion the limiting step seems to be the attack of the $\mathrm{C}-\mathrm{H}$ bond to this intermediate [24], which is due the lo much lower donor character of this $\sigma$-bond as compared to the $\pi$-bond of the alkene. Due to this difference the insertion reaction is much more difficult than cyclopropanation, given that the side dimerization of the diazocompound to yield maleate and fumarate derivatives competes much more efficiently, mainly in the case of the more reactive ethyl diazoacetate.

In this paper we report our first results in the application of simple $\mathrm{Cu} /$ silica and $\mathrm{Cu} /$ silicaalumina heterogeneous catalysts for the insertion of methyl phenyldiazoacetate (Scheme 1) and ethyl diazoacetate (Scheme 2) into the $\mathrm{C}-\mathrm{H}$ bond of THF. Two heterogeneous catalysts, very different as far as the nature of active species is concerned, are compared and characterized before and after the catalytic reaction, thus shedding some light into the role of the support in stabilizing the active copper oxidation state in this reaction.

\section{Experimental}

\subsection{Preparation of the catalysts}

Catalysts were prepared by the chemisorption-hydrolysis method [25-27]. Two different supports were used: $\mathrm{SiO}_{2}-\mathrm{Al}_{2} \mathrm{O}_{3}\left(13 \%\right.$ alumina, surface area $485 \mathrm{~m}^{2} \mathrm{~g}^{-1}$, pore volume 0.79 $\mathrm{ml} \mathrm{g}^{-1}$, pore radius $33 \AA$ ) and silica gel $\left(300 \mathrm{~m}^{2} \mathrm{~g}^{-1}, 1.70 \mathrm{ml} \mathrm{g}^{-1}, 114 \AA\right)$.

The powder was added to a $\left[\mathrm{Cu}\left(\mathrm{NH}_{3}\right)_{4}\right]^{2+}$ solution prepared by dropping aqueous $\mathrm{NH}_{3}$ to a $\mathrm{Cu}\left(\mathrm{NO}_{3}\right)_{2} \cdot 3 \mathrm{H}_{2} \mathrm{O}$ solution until $\mathrm{pH} 9$ had been reached. After 20 min under stirring, the 
slurry, held in an ice bath at $273 \mathrm{~K}$, was diluted with water. The solid was separated by filtration, washed with water, dried overnight at $383 \mathrm{~K}$, and calcined in air at $673 \mathrm{~K}$.

\subsection{Characterization of the catalysts}

EXAFS (Extended X-ray Absorption Fine Structure Spectroscopy) and XANES (Near Edge X-ray Absorption Spectroscopy) spectra have been recorded at the XAFS beamline of ELETTRA synchrotron (Trieste, Italy). Measurements were performed at room temperature in the transmission mode using a double-crystal $\mathrm{Si}(111)$ monochromator and beam intensity was measured before and after samples and reference foils by ionization chambers. Harmonic rejection was obtained by an appropriate choice of the gaseous mixture in the ionization chambers and by a $10 \%$ de-tuning of the crystal. Three spectra have been acquired and averaged for each sample. Spectra were recorded at the $\mathrm{Cu}$ K-edge (8978.9 $\mathrm{eV}$ ) working at a sampling step of $0.2 \mathrm{eV}$ around the edge and of $2 \mathrm{eV}$ over a range of 1 $\mathrm{keV}$ above the edge. An integration time of $2 \mathrm{sec}$ was used for all the points. $\mathrm{Cu}$ foil, $\mathrm{Cu}_{2} \mathrm{O}$ and $\mathrm{CuO}$ samples were also measured as reference materials.

Data analysis has been performed with the FEFF8 software package. Theoretical phase and amplitude functions for each pair were calculated with the FEFF8 potential modulus and were checked from the back-Fourier-transformed filtered peaks of the references sample spectra, getting a good agreement. The spectra have been extracted up to $15 \AA^{-1}$ with a good signal-to-noise ratio and analyzed in the typical k range from 2.5 to $13.5 \AA^{-1}$. The best fits of the extracted $\mathrm{k}^{3} \chi(\mathrm{k})$ signals were determined by a least-squares spherical curve fitting procedure. The parameter error bars were calculated from the experimental standard deviation derived from the averaging of the extracted $\chi(\mathrm{k})$ function. The $\mathrm{F}$ test was applied when necessary to distinguish between fits of similar quality. 
TPR analysis was performed with a modified version of the Micromeritics Pulse Chemisorb 2700 apparatus. Catalysts $(25 \mathrm{mg})$ were diluted with an equal amount of quartz, calcined at $500^{\circ} \mathrm{C}$ under $\mathrm{O}_{2}(40 \mathrm{~mL} / \mathrm{min})$ and then reduced at $8^{\circ} \mathrm{C} / \mathrm{min}$ under a flow $(15$ $\mathrm{mL} / \mathrm{min}$ ) of a $8 \% \mathrm{H}_{2} /$ Ar mixture.

Metal loadings were determined by inductively coupled plasma (ICP)-QMS (X series II, Thermo Fisher Scientific) and an external calibration methodology, after microwave digestion of fresh and used catalysts in $\mathrm{HNO}_{3}$.

\subsection{Catalytic tests}

Methyl phenyldiazoacetate was prepared by reaction of methyl phenylacetate with $p$ acetamidobencenesulfonylazide [28]. A suspension of dried heterogeneous catalyst (amount corresponding to $0.02 \mathrm{mmol} \mathrm{Cu})$ in anhydrous THF $(10 \mathrm{~mL}$, with $100 \mathrm{mg}$ of $\mathrm{n}$ decane as internal standard) was heated under reflux under an inert atmosphere. A solution of diazocompound $(1 \mathrm{mmol})$ in anhydrous THF $(10 \mathrm{~mL})$ was slowly added during $2 \mathrm{~h}$ with a syringe pump. Once the addition had finished, the reaction mixture was stirred and heated under reflux for $30 \mathrm{~min}$. The catalyst was filtered off and washed with THF $(5 \mathrm{~mL})$. The yield and stereoselectivity were determined by GC. The presence of active copper species in solution was tested by analysis after addition of diazocompound and heating under reflux for $2 \mathrm{~h}$. The catalyst was dried under vacuum and reused under the same conditions. When reactions were carried out in the presence of a chiral ligand, the enantioselectivity was determined by HPLC [13]. 


\section{Results and discussion}

\subsection{Preparation and characterization of the catalysts}

All the catalysts were prepared by the previously described chemisorption-hydrolysis method [25-27]. Several copper loadings were tried to determine the effect on the catalytic activity. The use of silica or silica-alumina support conditions the nature of the catalytic sites as demonstrated by the EXAFS and XANES spectra of the $\mathrm{Cu} 8 \% \mathrm{SiO}_{2}$ and $\mathrm{Cu} 4 \% \mathrm{SiO}_{2}-\mathrm{Al}_{2} \mathrm{O}_{3}$ reported in Fig. 1. The FFT EXAFS spectrum of the fresh $\mathrm{Cu} 8 \% \mathrm{SiO}_{2}$ sample (Fig. 1Aa) shows only one peak corresponding to a $\mathrm{Cu}-\mathrm{O}$ neighbor shell, fitted with about 6 oxygen atoms at $1.95 \AA$. The second peak at about $3 \AA$ corresponds to the next near $\mathrm{Cu}-\mathrm{Cu}$ neighbor shell characteristic of copper oxides, indicating the presence of bulk oxide aggregates. From previous studies [27] this structure is known to consist of an oxidehydroxide phase. The energy edge value of the XANES spectrum for this sample (Fig. $1 \mathrm{Ab}$ ) shows that all copper is present as $\mathrm{Cu}$ (II).

In the case of catalysts on silica-alumina (Fig. 1B), isolated $\mathrm{Cu}^{\delta+}(1 \leq \delta \leq 2)$ species account for almost all the surface metal. Only one peak corresponding to a $\mathrm{Cu}-\mathrm{O}$ neighbor shell, fitted with about 6 oxygen atoms at $1.95 \AA$ is recorded, whereas no next neighbor shells are present, indicating the presence of isolated copper ions only, with no formation of oxide aggregates.

Fig. 2 represents the superimposition of TPR profiles of $\mathrm{Cu} 8 \% \mathrm{SiO}_{2}$ and $\mathrm{Cu} 4 \% \mathrm{SiO}_{2}-\mathrm{Al}_{2} \mathrm{O}_{3}$. In the first case only the presence of a single peak with a maximum reduction temperature at $221^{\circ} \mathrm{C}$ was recorded. Such a reduction profile is diagnostic of the presence of highly dispersed $\mathrm{CuO}$ in a single and easily reducible state, significantly different from what observed for catalysts prepared by simple impregnation, in agreement with literature data 
[29-31]. On the contrary the profile of $\mathrm{Cu} 4 \% \mathrm{SiO}_{2}-\mathrm{Al}_{2} \mathrm{O}_{3}$ shows two peaks at 279 and $385^{\circ} \mathrm{C}$. According to the literature $[32,33]$ and to previous work by some of us with this type of solids [26] the lower temperature peak $\left(279^{\circ} \mathrm{C}\right)$ can be assigned to oxocations-like species of $[\mathrm{Cu}-\mathrm{O}-\mathrm{Cu}]^{2+}$ type, while the higher temperature peak $\left(385^{\circ} \mathrm{C}\right)$ shows the existence of isolated ionic copper species.

The different behavior towards reduction is better evidenced by comparing the EXAFS spectra of the reduced samples (Fig. 1). The reduction of the copper oxide particles obtained on silica leads to $\mathrm{Cu}(0)$, with parameters similar to copper foil used as reference. The FFT EXAFS spectrum of the sample $\mathrm{Cu} 8 \% \mathrm{SiO}_{2}$ after in-situ reduction in $\mathrm{H}_{2}$ flow at $270^{\circ} \mathrm{C}$ (Fig. 1-Aa) shows only one intense peak at about $2.5 \AA$ (not phase corrected) in agreement with the first $\mathrm{Cu}-\mathrm{Cu}$ neighbor shell of $\mathrm{Cu}$ foil, indicating the formation of very small metal particles (30 ̊̊ average diameter) under reduction conditions. The edge energy value in the XANES spectrum of the reduced sample (Fig. 1-Ab) evidences that all copper is present as $\mathrm{Cu}(0)$ atoms.

On the contrary, the FFT EXAFS spectrum of the sample $\mathrm{Cu} 4 \% \mathrm{SiO}_{2}-\mathrm{Al}_{2} \mathrm{O}_{3}$ after reduction (Fig. 1-Ba) still shows only the peak corresponding to the first $\mathrm{Cu}-\mathrm{O}$ neighbor shell, now fitted with about 4 oxygen atoms at $1.84 \AA$. No next neighbor shells are present, indicating no formation of metal aggregates under reduction conditions and the edge energy value in the XANES spectrum of the reduced sample (Fig. 1-Bb) evidences that copper is still present as $\mathrm{Cu}(\mathrm{I})$ atoms.

\subsection{Catalytic tests}

All the solids were tested as catalysts for the insertion of methyl phenyldiazoacetate in the C-H bond of THF (Scheme 1), using this reagent as the reaction solvent. The results 
obtained are gathered in Table 1. The yield results are representative for chemoselectivity due to the reaction mechanism. In fact the first step of the reaction is the formation of a $\mathrm{Cu}(\mathrm{I})$-carbene intermediate, from which the reaction can follow several competitive pathways. The most important ones are the formation of the two stereoisomers (anti and syn) of the insertion reaction and the formation of the two $(Z$ and $E$ ) alkenes coming from the dimerization of the diazocompound (Scheme 1). In this regard yield does not reflect catalytic activity related to diazocompound conversion, as in all reactions with fresh catalyst total conversion of this reagent is obtained, but the relative activity of insertion with respect to the side reactions.

The results obtained show that all the solids promote the insertion reaction with yields lower, in some cases only slightly lower, than those obtained in solution with $\mathrm{Cu}(\mathrm{OTf})_{2}$, but in all cases better than yield obtained with copper-exchanged laponite. This may be due to a higher coordinating ability of laponite acting as copper counterion. In fact the use of a copper salt with a highly coordinating anion, such as chloride, in homogeneous phase leads to no detectable amounts of insertion products, a negative effect already observed in the related cyclopropanation reaction $[34,35]$.

The most evident feature is the excellent performance of catalysts supported on silicaalumina. Not only all of them allow obtaining yields around $30 \%$, but also they do not loose activity in the second run. On the contrary, $\mathrm{Cu} / \mathrm{SiO}_{2}$ catalysts give a lower yield that in turn decreases very much in the second run.

A relevant point is the influence of the solid on the diastereoselectivity of the reaction. It is important to realize that the observed changes in selectivity correspond to variations of only a few calories in the energy difference between the transition states leading to the different products, therefore the lower syn/anti ratio observed in all cases may be ascribed to 
different reasons. Although it might be due to the different electronic nature of the catalytic sites $[34,35]$, most probably it may be due to the steric interaction between the solid support and the copper-carbene intermediate, which modifies the energies of the transition states leading to the different diastereoisomers [36] slightly favoring the transition state in which the bigger groups are placed far from the solid surface.

The use of silica-alumina as a support led to the best results. Yields are only slightly lower than those obtained in solution and do not depend on the copper content of the solid. An important point is to determine whether these solids act as truly heterogeneous catalysts or they behave as copper reservoirs that slowly leach active species to solution. Therefore all the catalysts were filtered under the reaction conditions and the progress of the reaction in solution was monitored (last column in Table 1). In all cases leaching of active species was almost negligible. Furthermore the solids were recovered with almost the same results, showing that no deactivation occurred after one run.

In view of these promising results, the same catalysts were tested in a more difficult reaction, namely the insertion of ethyl diazoacetate in the same $\mathrm{C}-\mathrm{H}$ bond. This more reactive diazocompound has a higher tendency to give side reactions, in particular carbene dimerization to maleate and fumarate, and as a consequence leads to lower yields in insertion products (Scheme 2). The results obtained (Table 2) show that silica- alumina catalysts are more active towards the insertion reaction, and mainly more stable than those supported on silica. In this case there is not a noticeable influence of copper content. Surprisingly solid catalysts lead to higher yields than $\mathrm{Cu}(\mathrm{OTf})_{2}$ which may be due to the great importance of site isolation with this more reactive diazocompound.

Previous results showed that carbene insertion is a ligand accelerated reaction [13]. In fact with $\mathrm{Cu}(\mathrm{II})$-exchanged laponite the yield of insertion of phenyldiazoacetate into THF 
increases from 21 to $27-66 \%$ when copper is forming a complex with a bis(oxazoline) or azabis(oxazoline) ligand. The ligand used in this work is a chiral bis(oxazoline) (Scheme 3) whose selection is due to a couple of reasons. On the one hand it is a cheap and easily prepared ligand [37] that is more stable that the related non-chiral ligand. On the other, although enantioselection is not the main aim of this work (values expected with this ligand are in the order of $50 \%$ ee for phenyldiazoacetate [13]) the obtained enantioselectivity can be used to prove the interaction of the ligand with the catalytic sites in the solid. The results obtained (Table 3) show that the use of ligand increases the yield, according to a ligandaccelerated reaction, and the enantioselectivity lays within the values expected for this ligand. Catalyst recovery leads to a parallel decrease in both yield and enantioselectivity. In fact the complete loss of enantioselectivity is accompanied by a yield drop up to the levels reached with the original solid. Additionally, when this recovered catalyst is treated with the same amount of chiral ligand, both yield and selectivity recover the original values, in spite of the slight leaching of copper observed.

The increase in yield of the diazoacetate insertion is really important (Table 3). Although the lack of precedents for this reaction in an enantioselective way, the lack of chromophores for UV detection, and the fact that both enantiomers could not be separated using chiral gas chromatography, hindered the determination of the enantioselection, the increase in yield demonstrated the effect of the ligand. The decrease in yield after recovery is in part due to $\mathrm{Cu}$ leaching but also to loss of ligand (Table 3).

The different behavior of the catalysts depending on the support is in good agreement with the different redox properties of the supported $\mathrm{Cu}$ phase.

The insertion reaction is catalyzed by $\mathrm{Cu}(\mathrm{I})$, and the $\mathrm{Cu}(\mathrm{II})$ species in the freshly prepared catalysts is in situ reduced by the diazocompound. EXAFS spectra (Fig. 1) show that ionic 
$\mathrm{Cu}$ (II) species on the surface of $\mathrm{Cu} / \mathrm{SiO}_{2}-\mathrm{Al}_{2} \mathrm{O}_{3}$ catalysts are easily reduced to $\mathrm{Cu}$ (I) in $\mathrm{H}_{2}$ flow, whereas supported $\mathrm{CuO}$ is much more easily reduced to $\mathrm{Cu}(0)$. Formation of the active $\mathrm{Cu}(\mathrm{I})$ species in this last case can be due to comproportionation of $\mathrm{Cu}(0)$ with the initial $\mathrm{Cu}(\mathrm{II})$ species as recently shown for homogeneous $\mathrm{C}-\mathrm{O}$ couplings [38]. This process would result in non quantitative conversion of $\mathrm{Cu}(\mathrm{II})$ to $\mathrm{Cu}(\mathrm{I})$ and then to lower activity of the $\mathrm{Cu} / \mathrm{SiO}_{2}$ catalysts. Moreover this series of reactions would induce $\mathrm{Cu}$ leaching from the surface as no surface reorganization was deduced from the EXAFS of the after catalysis sample (Fig. 3). Analysis of the used catalysts, after washing with methanol to remove organic residues, shows very low copper loss for $\mathrm{Cu} 4 \% \mathrm{SiO}_{2}-\mathrm{Al}_{2} \mathrm{O}_{3}$ whereas $\mathrm{Cu} 8 \% \mathrm{SiO}_{2}$ looses about one third of the total metal content $(28 \%)$. In turn, the lower $\mathrm{Cu}$ content may be the reason for its lower activity in the second run.

The FFT EXAFS spectrum of the sample $\mathrm{Cu} 8 \% \mathrm{SiO}_{2}$ after catalysis run (Fig. 3-Aa) again shows two peaks corresponding to the $\mathrm{Cu}-\mathrm{O}$ and $\mathrm{Cu}-\mathrm{Cu}$ neighbor shells of copper oxide phase. The sample structure around copper sites is totally unchanged upon catalysis reaction with respect to the fresh catalyst. The edge energy value in the XANES spectrum of the $\mathrm{Cu} 8 \% \mathrm{SiO}_{2}$ after catalysis sample (Fig. 3-Ab), evidences that copper is still entirely present as $\mathrm{Cu}(\mathrm{II})$ atoms. In fact filtration in the open air should produce the easy reoxidation of $\mathrm{Cu}(\mathrm{I})$ species to $\mathrm{Cu}(\mathrm{II})$, and these studies show that the nature of the catalytic species does not change during the reduction-oxidation process in the reaction and filtration procedure.

On the contrary, the edge energy value in the XANES spectrum of the sample $\mathrm{Cu} 4 \% \mathrm{SiO}_{2}$ $\mathrm{Al}_{2} \mathrm{O}_{3}$ after catalysis run (Fig. 3-Bb black line), shows that all copper is present as $\mathrm{Cu}(\mathrm{I})$ atoms. 
The elegant work of Salomon and Kochi [39] on the mechanism of cyclopropanation reaction with diazocompounds shows that it is very difficult to identify the oxidation state of the active $\mathrm{Cu}$ phase in this reaction when copper(II) compounds are nominally employed as catalysts. They are reduced to the $\mathrm{Cu}(\mathrm{I})$ state by the diazocompound but disproportionation of $\mathrm{Cu}(\mathrm{I})$ to colloidal forms of $\mathrm{Cu}(0)$ and inactive $\mathrm{Cu}$ (II) is almost unavoidable in the absence of coordinating ligands. In the case here reported, the support itself act as a strong stabilizer of $\mathrm{Cu}(\mathrm{I})$ in the $\mathrm{Cu} / \mathrm{SiO}_{2} \mathrm{Al}_{2} \mathrm{O}_{3}$ series, thus making these catalysts not only more active but also much more stable than the $\mathrm{Cu} / \mathrm{SiO}_{2}$ ones.

\section{Conclusions}

The results obtained show for the first time that purely inorganic $\mathrm{Cu}$-on-silica-alumina is an efficient catalyst for carbene transfer reactions, which does not require the presence of a ligand to be active. Its activity is related to the easy reduction of the original isolated $\mathrm{Cu}$ (II) sites to $\mathrm{Cu}(\mathrm{I})$ obtained by reaction with the diazocompound and to the stability of this ionic species on the surface, avoiding leaching of active phase and therefore allowing reuse of the catalyst. From these results the development of new solids able to stabilize isolated $\mathrm{Cu}$ (I) sites can be envisaged as a way to improve the yield of $\mathrm{C}-\mathrm{H}$ carbene insertion reactions with purely inorganic materials. In the meantime the ligand acceleration of the reaction, probably related to the higher stability of $\mathrm{Cu}$ (I) in the presence of the ligand, allows its application to less selective diazocompounds, such as diazoacetate, and opens the way to the use of these solids in enantioslective reactions. Further work to extent the applicability of these solids to other reactions in the same family are in course. 


\section{Acknowledgements}

This work was made possible by the financial support of the Ministerio de Ciencia e Innovación (projects CTQ2008-05138 and Consolider Ingenio CSD2006-0003), the European Commission (IDECAT Network of Excellence), and the Diputación General de Aragón (E11 Group co-financed by the European Regional Development Funds).

\section{References}

[1] F. Monnier, M. Taillefer, Angew. Chem. Int. Ed. 48 (2009) 6954.

[2] G. Evano, N. Blanchard, M. Toumi, Chem.Rev. 108 (2008) 3054.

[3] K. Kunz, U. Scholz, D. Ganzer, Synlett (2003) 2428.

[4] A. Biffis, E. Scattolin, N. Ravasio, F. Zaccheria, Tetrahedron Lett. 48 (2007) 8761.

[5] M. P. Doyle, R. Duffy, M. Ratnikov, L. Zhou, Chem. Rev. 110 (2010) 704.

[6] H. M. L. Davies, R. E. J. Beckwith, Chem. Rev. 103 (2003) 2861.

[7] H. M. L. Davies, Angew. Chem., Int. Ed. 45 (2006) 6422.

[8] J. Urbano, T. R. Belderraín, M. C. Nicasio, S. Trofimenko, M. M. Díaz-Requejo, P. J. Pérez, Organometallics 24 (2005) 1528.

[9] A. Caballero, M. M. Díaz-Requejo, T. R. Belderraín, M. C. Nicasio, S. Trofimenko, P. Pérez, J. Am. Chem. Soc. 125 (2003) 1446.

[10] A. Caballero, M. M. Díaz-Requejo, T. R. Belderraín, M. C. Nicasio, S. Trofimenko, P. Pérez, Organometallics 22 (2003) 4145.

[11] A. G. H. Wee, J. Org. Chem. 66 (2001) 8513.

[12] M. P. Doyle, W.Hu, J. Org. Chem. 65 (2000) 8839.

[13] J. M. Fraile, J. I. García, J. A. Mayoral, M. Roldán, Org. Lett. 9 (2007) 731. 
[14] C. J. Flynn, C. J. Elcoate, S. E. Lawrence, A. R. Maguire, J. Am. Chem. Soc. 132 (2010) 1184.

[15] C. R. Slattery, A. R. Maguire, Org. Biomol. Chem. 9 (2011) 667.

[16] H. M. L. Davies, A. M. Walji, Org. Lett. 5 (2003) 479.

[17] H. M. L. Davies, A. M. Walji, T. Nagashima, J. Am. Chem. Soc. 126 (2004) 4271.

[18] K. Takeda, T. Oohara, M. Anada, H. Nambu, S. Hashimoto, Angew. Chem. Int. Ed. 49 (2010) 6979.

[19] J. C. Oudejans, J. Kaminska, A. C. Kockvandalen, H. Van Bekkum, Rec. Trav. Chim. Pays-Bas 105 (1986) 421.

[20] J. M. Fraile, J. I. García, J. A. Mayoral, Chem. Commun. (1996) 1319.

[21] J. S. Yadav, B. V. Subba Reddy, K. V. Purnima, K. Nagaiah, N. Lingaiah, J. Mol. Catal. A 285 (2008) 36.

[22] X. Liu, Y. Liu, X. Li, S. Xiang, Y. Zhang, P. Ying, Z. Wei, C. Li, Appl. Catal. A 239 (2003) 279.

[23] J. M. Fraile, J. I. García, V. Martínez-Merino, J. A. Mayoral, L. Salvatella, J. Am. Chem. Soc. 123 (2001) 7616.

[24] S. Rodríguez-Rodríguez, Ph. D. Dissertation, University of Zaragoza.

[25] F. Boccuzzi, A. Chiorino, G. Martra, M. Gargano, N. Ravasio, B. Carrozzini, J. Catal. 165 (1997) 129.

[26] S. Bennici, A. Gervasini, N. Ravasio, F. Zaccheria, J. Phys. Chem. B 107 (2003) 5168.

[27] A. Gervasini, M. Manzoli, G. Martra, A. Ponti, N. Ravasio, L. Sordelli, F. Zaccheria, J. Phys. Chem. B 110 (2006) 7851.

[28] W. A. J. Starmans, L. Thijs, B. Zwanenburg, Tetrahedron 54 (1998) 629.

[29] G. C. Bond, S. N. Namijo, J. S. Wakeman, J. Mol. Catal. 64, 1991, 305. 
[30] G. C. Bond, S. N. Namijo, J. Catal. 118 (1989) 507.

[31] F. Boccuzzi, S. Coluccia, G. Martra, N. Ravasio, J. Catal. 184 (1999) 316.

[32] T. Beutel, J. Sárkány, G.-D. Lei, J. Y. Yan, W. M. H. Sachtler, J. Phys. Chem. 100 (1996) 845.

[33] R. Bulánek, B. Wichterlová, Z. Sobalík, J. Tichý, Appl. Catal. B 31 (2001) 13.

[34] J. M. Fraile, J. I. García, J. A. Mayoral, T. Tarnai, J. Mol. Catal. A 144 (1999) 85.

[35] J. M. Fraile, J. I. García, M. J. Gil, V. Martínez-Merino, J. A. Mayoral, L. Salvatella, Chem. Eur. J. 10 (2004) 758.

[36] For support effects on selectivity see: J. M. Fraile, J. I. García, C. I. Herrerías, J. A. Mayoral, E. Pires, Chem. Soc. Rev. 38 (2009) 695.

[37] A. Cornejo, J. M. Fraile, J. I. García, M. J. Gil, V. Martínez-Merino, J. A. Mayoral, E. Pires, I. Villalba, Synlett (2005) 2321.

[38] G. Franc, A. Jutand, Dalton Trans. 39 (2010) 7873.

[39] R. G. Salomon, J. K. Kochi, J. Am. Chem. Soc. 95 (1973) 3300. 
Table 1. Results in the insertion of methyl phenyldiazoacetate in THF.

\begin{tabular}{|c|c|c|c|c|}
\hline Catalyst & Run & Yield $(\%)^{\mathrm{a}}$ & syn/anti ${ }^{\mathrm{a}}$ & $\begin{array}{c}\text { Homogeneous } \\
\text { yield }^{\mathrm{b}}\end{array}$ \\
\hline $\mathrm{Cu}(\mathrm{OTf})_{2}$ & 1 & 41 & $75 / 25$ & - \\
\hline $\mathrm{Cu}$-Laponite & 1 & 21 & $56 / 44$ & n.d. \\
\hline \multirow[t]{2}{*}{$\mathrm{Cu} 4 \% \mathrm{SiO}_{2}-\mathrm{Al}_{2} \mathrm{O}_{3}$} & 1 & 34 & $59 / 41$ & 2 \\
\hline & 2 & 32 & $58 / 42$ & 4 \\
\hline \multirow[t]{2}{*}{$\mathrm{Cu} 6 \% \mathrm{SiO}_{2}-\mathrm{Al}_{2} \mathrm{O}_{3}$} & 1 & 34 & $59 / 41$ & 4 \\
\hline & 2 & 32 & $60 / 40$ & 2 \\
\hline \multirow[t]{2}{*}{$\mathrm{Cu} 9 \% \mathrm{SiO}_{2}-\mathrm{Al}_{2} \mathrm{O}_{3}$} & 1 & 31 & $59 / 41$ & 5 \\
\hline & 2 & 30 & $59 / 41$ & 1 \\
\hline \multirow[t]{2}{*}{$\mathrm{Cu} 2 \% \mathrm{SiO}_{2}$} & 1 & 21 & $61 / 39$ & 5 \\
\hline & 2 & 9 & $60 / 40$ & 11 \\
\hline \multirow[t]{2}{*}{$\mathrm{Cu} 8 \% \mathrm{SiO}_{2}$} & 1 & 26 & $59 / 41$ & 3 \\
\hline & 2 & 14 & $60 / 40$ & n.d. \\
\hline
\end{tabular}

\footnotetext{
${ }^{a}$ Determined by GC. ${ }^{b}$ After filtration, a new portion of diazocompound was added to the solution. Homogeneous yield $=$ Total yield after addition - Yield in the presence of solid.
} 
Table 2. Results in the insertion of ethyl diazoacetate in THF.

\begin{tabular}{lccc}
\hline Catalyst & Run & ${\text { Yield }(\%)^{\mathrm{a}}}$ & Homogeneous yield $^{\mathrm{b}}$ \\
\hline $\mathrm{Cu}(\mathrm{OTf})_{2}$ & 1 & 8 & - \\
$\mathrm{Cu}$-Laponite & 1 & 11 & n.d. \\
$\mathrm{Cu} 4 \% \mathrm{SiO}_{2}-\mathrm{Al}_{2} \mathrm{O}_{3}$ & 1 & 19 & 4 \\
& 2 & 28 & n.d. \\
$\mathrm{Cu} 6 \% \mathrm{SiO}_{2}-\mathrm{Al}_{2} \mathrm{O}_{3}$ & 1 & 27 & 1 \\
& 2 & 24 & n.d. \\
$\mathrm{Cu} \% \% \mathrm{SiO}_{2}-\mathrm{Al}_{2} \mathrm{O}_{3}$ & 1 & 27 & 2 \\
& 2 & 19 & n.d. \\
$\mathrm{Cu} 2 \% \mathrm{SiO}_{2}$ & 1 & 17 & 8 \\
$\mathrm{Cu} 8 \% \mathrm{SiO}_{2}$ & 2 & 18 & 0 \\
& 1 & 24 & 6
\end{tabular}

${ }^{a}$ Determined by GC. ${ }^{b}$ After filtration, a new portion of diazocompound was added to the solution. Homogeneous yield $=$ Total yield after addition - Yield in the presence of solid. 
Table 3. Results in the insertion of methyl phenyldiazoacetate (PhDiaz) and ethyl diazoacetate (Diaz) in THF in the presence of chiral bis(oxazoline).

\begin{tabular}{|c|c|c|c|c|c|c|c|}
\hline Catalyst & Diazocompound & Run & Yield $(\%)^{\mathrm{a}}$ & syn/anti ${ }^{\mathrm{a}}$ & $\%$ ee $\operatorname{syn}^{\mathrm{b}}$ & $\%$ ee $a n t i^{b}$ & $\begin{array}{c}\text { Homogeneous } \\
\text { yield }^{\mathrm{c}}\end{array}$ \\
\hline $\mathrm{Cu}(\mathrm{OTf})_{2}$ & PhDiaz & 1 & 48 & $64 / 36$ & 59 & 40 & - \\
\hline \multirow[t]{4}{*}{$\mathrm{Cu} 1.3 \% \mathrm{SiO}_{2}-\mathrm{Al}_{2} \mathrm{O}_{3}$} & PhDiaz & 1 & 62 & $54 / 46$ & 48 & 52 & n.d. \\
\hline & & 2 & 49 & $57 / 43$ & 34 & 44 & n.d. \\
\hline & & 3 & 34 & $65 / 35$ & 0 & 5 & n.d. \\
\hline & & $4^{\mathrm{d}}$ & 46 & $52 / 48$ & 47 & 53 & $9^{\mathrm{e}}$ \\
\hline \multirow[t]{3}{*}{$\mathrm{Cu} 4 \% \mathrm{SiO}_{2}-\mathrm{Al}_{2} \mathrm{O}_{3}$} & PhDiaz & 1 & 80 & $54 / 46$ & 53 & 49 & n.d. \\
\hline & & 2 & 75 & $54 / 46$ & 46 & 51 & n.d. \\
\hline & & 3 & 49 & $60 / 40$ & 15 & 21 & n.d. \\
\hline \multirow[t]{2}{*}{$\mathrm{Cu} 1.3 \% \mathrm{SiO}_{2}-\mathrm{Al}_{2} \mathrm{O}_{3}$} & Diaz & 1 & 32 & - & - & - & 2 \\
\hline & & 2 & 26 & - & - & - & n.d. \\
\hline \multirow[t]{2}{*}{$\mathrm{Cu} 4 \% \mathrm{SiO}_{2}-\mathrm{Al}_{2} \mathrm{O}_{3}$} & Diaz & 1 & 63 & - & - & - & 16 \\
\hline & & 2 & 41 & - & - & - & n.d. \\
\hline
\end{tabular}


${ }^{a}$ Determined by GC. ${ }^{b}$ Determined by HPLC (Chiralcel OD-H). ${ }^{c}$ After filtration, a new portion of diazocompound was added to the solution. Homogeneous yield $=$ Total yield after addition - Yield in the presence of solid. ${ }^{\mathrm{d}}$ A new amount of fresh ligand is added. ${ }^{\mathrm{e}}$ The active species in solution is not enantioselective. 


\section{Captions for Schemes and Figures}

Scheme 1. Insertion reaction of methyl phenyldiazoacetate in THF.

Scheme 2. Insertion reaction of ethyl diazoacetate in THF.

Scheme 3. Enantioselective insertion reaction of methyl phenyldiazoacetate in THF.

Figure 1. A) $\mathrm{Cu} 8 \% \mathrm{SiO}_{2}$ fresh sample and after reduction in $\mathrm{H}_{2}$ at $270^{\circ} \mathrm{C}$ : Aa) Fourier Transformed EXAFS spectra (not phase corrected); $\mathrm{Ab}$ ) $\mathrm{Cu}$ K-edge normalized XANES spectra. B) $\mathrm{Cu} 4 \% \mathrm{SiO}_{2}-\mathrm{Al}_{2} \mathrm{O}_{3}$ fresh sample and after reduction in $\mathrm{H}_{2}$ at $270^{\circ} \mathrm{C}: \mathrm{Ba}$ ) Fourier Transformed EXAFS spectra (not phase corrected); $\mathrm{Bb}$ ) $\mathrm{Cu}$ K-edge XANES spectra. For comparison the spectra of reference materials are reported ( $\mathrm{Cu}$ foil FFT not in scale).

Figure 2. TPR profiles of $\mathrm{Cu} 4 \% \mathrm{SiO}_{2}-\mathrm{Al}_{2} \mathrm{O}_{3}$ and $\mathrm{Cu} 8 \% \mathrm{SiO}_{2}$.

Figure 3. A) $\mathrm{Cu} 8 \% \mathrm{SiO}_{2}$ fresh sample and after catalysis run: Aa) Fourier Transformed EXAFS spectra (not phase corrected); $\mathrm{Ab}$ ) $\mathrm{Cu} \mathrm{K}$-edge normalized XANES spectra. B) $\mathrm{Cu} 4 \% \mathrm{SiO}_{2}-\mathrm{Al}_{2} \mathrm{O}_{3}$ fresh sample and after catalysis run: Ba) Fourier Transformed EXAFS spectra (not phase corrected); $\mathrm{Bb}$ ) $\mathrm{Cu} \mathrm{K}$-edge XANES spectra. For comparison the spectra of reference materials are reported ( $\mathrm{Cu}$ foil FFT not in scale). 